\title{
SECONDARY ORGANIC AEROSOL FORMATION FROM THE OZONOLYSIS AND OH-PHOTOOXIDATION OF 2,5-DIMETHYLFURAN
}

\author{
Mercedes Tajuelo' ${ }^{1}$ Diana Rodríguez ${ }^{1 *}$, Ana Rodríguez ${ }^{1}$, Alba Escalona ${ }^{2}$, Gabriela Viteri² ${ }^{2}$ \\ Alfonso Aranda ${ }^{2}$, Yolanda Diaz-de-Mera ${ }^{2}$
}

'Facultad de Ciencias Ambientales y Bioquímica, Universidad de Castilla La Mancha, Avenida Carlos III, s/n, 45071 Toledo, Spain.

${ }^{2}$ Facultad de Ciencias y Tecnologías Químicas, Universidad de Castilla La Mancha, Avenida Camilo José Cela 10, 13071 Ciudad Real, Spain.

*Corresponding author: diana.rodriguez@uclm.es

\section{Introduction}

All societies require energy services to meet basic human needs (e.g., lighting and transportation) and to serve productive processes. However, conventional oil and gas reserves are decreasing and, thus the capacity to meet the growing demand of energy will require the development of unconventional renewable sources (Khan et al., 2018). In addition to the depletion of fossil carbon reserves, the concerns about global climate change result in raising attention on renewable and environmentally friendly fuels which are cost-wise competitive with fossil fuels (Vasudevan et al., 2010). Thus, while solar, wind, hydroelectric, and geothermal energy have been proposed as alternatives to conventional sources for heat and electricity production in stationary power applications (Graziani and Fornasiero, 2007), biomass is already a significant renewable energy source and is expected to grow in importance in the transition away from fossil energy sources (Giele et al., 2019), at a relatively low cost. Moreover, it is considered to be an ideal substitute 
for oil in the production of fuels, chemicals and carbon-based materials since it is generated from available atmospheric $\mathrm{CO}_{2}$, water and sunlight through biological photosynthesis (Isikgor and Becer, 2015). Furthermore, biomass is a versatile energy source that can also be stored and converted to energy on-demand (De Meyer et al., 2014). However, biomass burning emissions is another large global source of non-fossil carbon in organic aerosol (OA), which has likely changed since preindustrial times (van der Werf et al., 2010; Bond et al., 2013; Andreae, 2019; Pérez Pastor et al., 2020). Currently, the biomass burning source of secondary organic aerosol (SOA) is not yet well constrained in global climate models (Spracklen et al., 2011; Tsigaridis et al., 2014; Shrivastava et al., 2015) even though the majority of carbonaceous aerosol on regional to global scales is thought to be of non-fossil fuel origin (Spracklen et al., 2011).

Lignocellulosic biomass, which is the most abundant biomass (Zhou et al. 2011), has critical importance as sustainable production of chemicals and fuels. Catalytic production methods of converting lignocellulosic biomass into furan derivatives have been improved significantly (Roman-Leshkov et al., 2007; Zhao et al., 2007; Lee and Park, 2020). One of these furan derivative, 2,5-dimethylfuran (2,5-DMF), which is also called a "sleeping giant" of renewable chemicals (Tong et al., 2010), has attracted long interest as a potential biofuel due to its physicochemical properties, in some aspects better than gasoline and ethanol (RomanLeshkov, 2007; Luque, 2008; Xu and Wang, 2016); and its low pollutant emissions, gaseous and particles, in its combustion (Daniel, 2012; Xu and Wang, 2016). Biological and chemical improvements to the catalytic conversion of biomass-derived carbohydrates (fructose or glucose) have made the large-scale and low-cost production of 2,5-DMF possible (Zhao, 2007; Mascal and Nikitin, 2008; Chidambaram and Bell, 2010; Thananatthanachon and Rauchfuss, 2010). However, if 2,5-DMF can be accepted as an alternative transport fuel, some outstanding problems must be resolved before it can be commercialized. One of them is its atmospheric fate, since 2,5-DMF could enter the atmosphere upon their extensive potential usage 
as biofuel or by direct emissions from biomass burning (savanna, grassland, forest, agriculture residues, etc.) (Andreae, 2019); and it could be degraded there by its reactions with $\mathrm{OH}, \mathrm{NO}_{3}, \mathrm{Cl}$ radicals and $\mathrm{O}_{3}$.

The reaction rate constant of 2,5-DMF with $\mathrm{O}_{3}$ in the atmosphere is significantly lower (4.2 \pm 0.9$) \times 10^{-16} \mathrm{~cm}^{3}$ molecule $\mathrm{e}^{-1} \mathrm{~s}^{-1}$ (Matsumoto, 2011) than its reaction with $\mathrm{OH}$ radical (12.5 \pm 0.4$) \times 10^{-11} \mathrm{~cm}^{3}$ molecule ${ }^{-1} \mathrm{~s}^{-1}$ at $298 \mathrm{~K}$ (Aschmann et al., 2011); however, considering the average atmospheric concentrations, $7 \times 10^{11}$ and $2 \times 10^{6}$ molecules $\mathrm{cm}^{-3}$ for $\mathrm{O}_{3}($ Logan, 1985) and OH radical (Hein et al., 1997), respectively, ozonolysis may be dominant, the expected rate of removal of 2,5-DMF due to $\mathrm{O}_{3}$ being about twice that due to $\mathrm{OH}$ radicals. The oxidation of 2,5DMF could form furan derivatives such as furanones which are efficient precursors of SOA.

SOA accounts for a large portion of the total fine aerosol burden (Jimenez et al., 2009). As a result, SOA also contributes significantly to the Earth's radiation balance through the absorption and scattering of solar radiation (Scott et al., 2014), and plays important roles in urban visibility (Ren et al., 2018), and health (Requia et al., 2018). Factors such as relative humidity (RH), NOx level and seed particles would influence the implication in SOA formation.

Although the SOA formation potential of furanes has been studied in recent years (GomezAlvarez et al., 2009; Jiang et al., 2019; Strollo and Ziemann, 2013; Joo et al., 2019), the SOA formation mechanisms are still poorly known. In this sense, the present study was initiated with the aim of studying the $\mathrm{OH}$ radical photooxidation and ozonolysis of 2,5-DMF to characterize the conditions that lead to the formation and growth of new particles. To our knowledge, this study of SOA formation from photooxidation and ozonolysis of 2,5-DMF has not been a subject of prior experimental investigations, although there is a previous work for $\mathrm{OH}$-photooxidation where the SOA yield of the mixture of isomers of 2,4-/2,5-dimethylfuran has been studied (Bruns et al., 2016). Moreover, the effect of 2,5-DMF concentration, $\mathrm{NOx}, \mathrm{RH}, \mathrm{SO}_{2}$ and different inorganic seed particles during the $\mathrm{OH}$ oxidation and the ozonolysis have been studied and 
discussed. These results can be used to estimate SOA formation from biomass burning emissions and improve our understanding of oxidation in biomass burning plumes.

\section{Experimental system}

\subsection{OH-Photooxidation}

The experiments were conducted in a $500 \mathrm{~L}$ Teflon chamber enclosed in an isothermal cabinet with six fluorescent lamps (Philips TUV G13, $36 \mathrm{~W}$ ) mounted on the walls. The chamber is operated at room temperature and atmospheric pressure and is flushed and filled with synthetic air until the particle number concentration, $\mathrm{PNbC}$, was $<20$ particles $\mathrm{cm}^{-3}$. Details of chamber operation are described in more detail in (Tajuelo et al., 2019a, 2019b) and are only summarized here.

Known volumes of styrene and a precursor of $\mathrm{OH}$ radical $\left(\mathrm{H}_{2} \mathrm{O}_{2}\right)$ were injected by means of microlitre syringes through a septum installed in one port of a union that was connected to the reactor; then, they were fluxed using a gentle flow of purified air by a mass flow controller. OH radicals were generated by photolysis $(\lambda=254 \mathrm{~nm})$ of $\mathrm{H}_{2} \mathrm{O}_{2}(60 \%$, Fisher Scientific). The amount of water necessary for a given RH was calculated and injected into the bubbler. The water was then evaporated and flushed inside the reactor using synthetic air. $\mathrm{RH}$ was varied in these experiments between $6 \%$ to $60 \%$ and it was measured with a hygrometer (HMT333, Vaisala). Moreover, NO was used for experiments in presence of NOx. It was introduced by flushing pure $\mathrm{N}_{2}$ through a calibrated glass bulb filled to a predetermined partial pressure of purified NO. The experimental conditions are summarized in Table S1 in the supplementary information. 
2,5-DMF was followed by chromatography-mass spectrometric detection (GC-MS, Shimadzu QP2010), using a capillary column (size: $30 \mathrm{~m} \times 0.32 \mathrm{~mm} \times 1 \mathrm{~m}$, Meta.X5 Teknokroma) maintained isothermally at $60{ }^{\circ} \mathrm{C}$. A chemiluminescence analyser (AC32 M, Envea Environnement) was used to measure the NOx concentration in the gas phase. The particle phase was monitored using a Fast Mobility Particle Sizer (FMPS; 3091 TSI) which provides particle size distribution over 32 size channels and total mass of particles with diameters within the range 5.6-560 nm (Aranda et al., 2015). The total aerosol mass concentration was calculated from the measured particle size distribution assuming unit density and spherical particles. For seeded experiments, ammonium sulphate $\left(\left(\mathrm{NH}_{4}\right)_{2} \mathrm{SO}_{4}\right)$ and calcium chloride $\left(\mathrm{CaCl}_{2}\right)$ were selected as inorganic salt. The seed particles were generated by atomization of a dilute aqueous salt solutions (0.01-0.07 mol/L) using a constant rate atomizer (TSI Inc., 3076), which were subsequently passed through a diffusion dryer (TSI Inc., 3062).

The $\mathrm{OH}$ radical concentration was estimated from the measured 2,5-DMF decay and the literature rate constant $\left(\mathrm{k}_{\mathrm{OH}+2,5-\mathrm{DMF}}=(12.5 \pm 0.4) \times 10^{-11} \mathrm{~cm}^{3}\right.$ molecule $\left.\mathrm{s}^{-1}\right)$ (Aschmann et al., 2011). The calculated average $\mathrm{OH}$ radical concentration $\left(5.97 \times 10^{6}\right.$ molecule $\left.\mathrm{cm}^{-3}\right)$ is within the same magnitude of the $12 \mathrm{~h}$ daytime average $\mathrm{OH}$ concentration in the troposphere (Hein et al., 1997).

\subsection{Reaction with $\mathrm{O}_{3}$}

Since the experimental setup and methodology to carry out ozonolysis experiments have been described in detail previously (Díaz-de-Mera, 2017; Bracco, 2019), only essential information is provided here. The experiments were carried out in a 200L capacity FEP collapsible chamber at room temperature. This reactor was coupled to a scanning mobility particle sizer (SMPS TSI 3938) with a condensation particle counting (CPC 3775) and a nano-differential mobility analyser (DMA 3881A) in order to monitor the concentration and size distribution of particles (particle size range from 5 to $150 \mathrm{~nm}$ ). The total mass concentration was derived from the measured 
particle size distribution assuming unit density and spherical particles. The reactor was also coupled to different detectors to analyse the gas phase: $\mathrm{SO}_{2}$ (Teledyne Instruments 101.E) and ozone (Envea, Environnement O342M).

The ozone generation was carried out with a high voltage electric discharge (BMT Messtechnik $802 \mathrm{~N}$ ) and its initial concentration measured with a UV spectrometer (Hamamatsu C10082CAH). Water vapour in the chamber was generated through evaporation, as in the $\mathrm{OH}$ - photooxidation experimental system. On the other hand, in order to avoid unwanted side reactions with the $\mathrm{OH}$ radicals that could be generated in the reactor, cyclohexane was added in excess, so that $>99 \%$ of the generated $\mathrm{OH}$ was scavenged. As in the $\mathrm{OH}$ radical study, after each experiment, the Teflon bag was repetitively washed with synthetic air. Experimental conditions have been included in Tabla S1.

\subsection{Reagents}

Reagents were obtained from commercial sources at the following purities:

2,5-Dimethylfuran ( $\geq 99 \%$ Sigma-Aldrich), hydrogen peroxide ( $>60 \%$, Fisher Chemical), nitric oxide ( $\geq 99,5 \%$, Linde), ammonium sulphate ( $99 \%$, Sigma-Aldrich), calcium chloride (99\%, Scharlau), cyclohexane $(99,5 \%$, Sigma-Aldrich), $\mathrm{SO}_{2}$ (99.9\%, Fluka), $\mathrm{O}_{2}$ (4X, Praxair). Synthetic air (99.999\%, Praxair) and $\mathrm{N}_{2}$ (99.999\%, Praxair) were employed as bath gases for the experiments, and $\mathrm{He}(99.998 \%$, Praxair) was used as GC carrier gas. Ultrapure water $(18.2 \mathrm{M} \Omega \mathrm{cm})$ was obtained from an LGA Purelab® Ultra water purification system (Veolia Water Technologies). Liquids reagents were purified by successive trap-to-trap distillation.

\section{Results and discussion}

\subsection{OH-Photooxidation experiments}


The concentration-time profile of SOA formation obtained for a 2,5-DMF (10 ppb) experiment without NOx and seed particles and RH level $<6 \%$ is shown in Fig. 1. The measured aerosol concentration had to be corrected for wall losses in each experiment due to particle wall deposition onto the Teflon film. Several methods have been used to account for particle wall deposition in SOA formation studies (i.e., the size dependent, number-averaged and volume-averaged methods); however, these methods are generally consistent with one another at low seed aerosol surface area $\left(<3000 \mathrm{~mm}^{2} \mathrm{~cm}^{-3}\right)(\mathrm{Nah}$ et al.,2017), so, the lamps were turned off when the SOA mass started to decrease, typically after reaction times in the order of 4-5 hours. The aerosol concentration was then followed for two additional hours and the wall loss kinetic rate constant was measured from a firstorder decay. Then applied the first-order mass-particle-wall deposition rate to the entire experiment to correct for particle wall los $\left(\mathrm{kw}=(5.3 \pm 0.2) \times 10^{-5} \mathrm{~s}^{-1}\right)$. Then, the SOA yield was estimated using the corrected OA mass concentration and the consumption of 2,5DMF. 

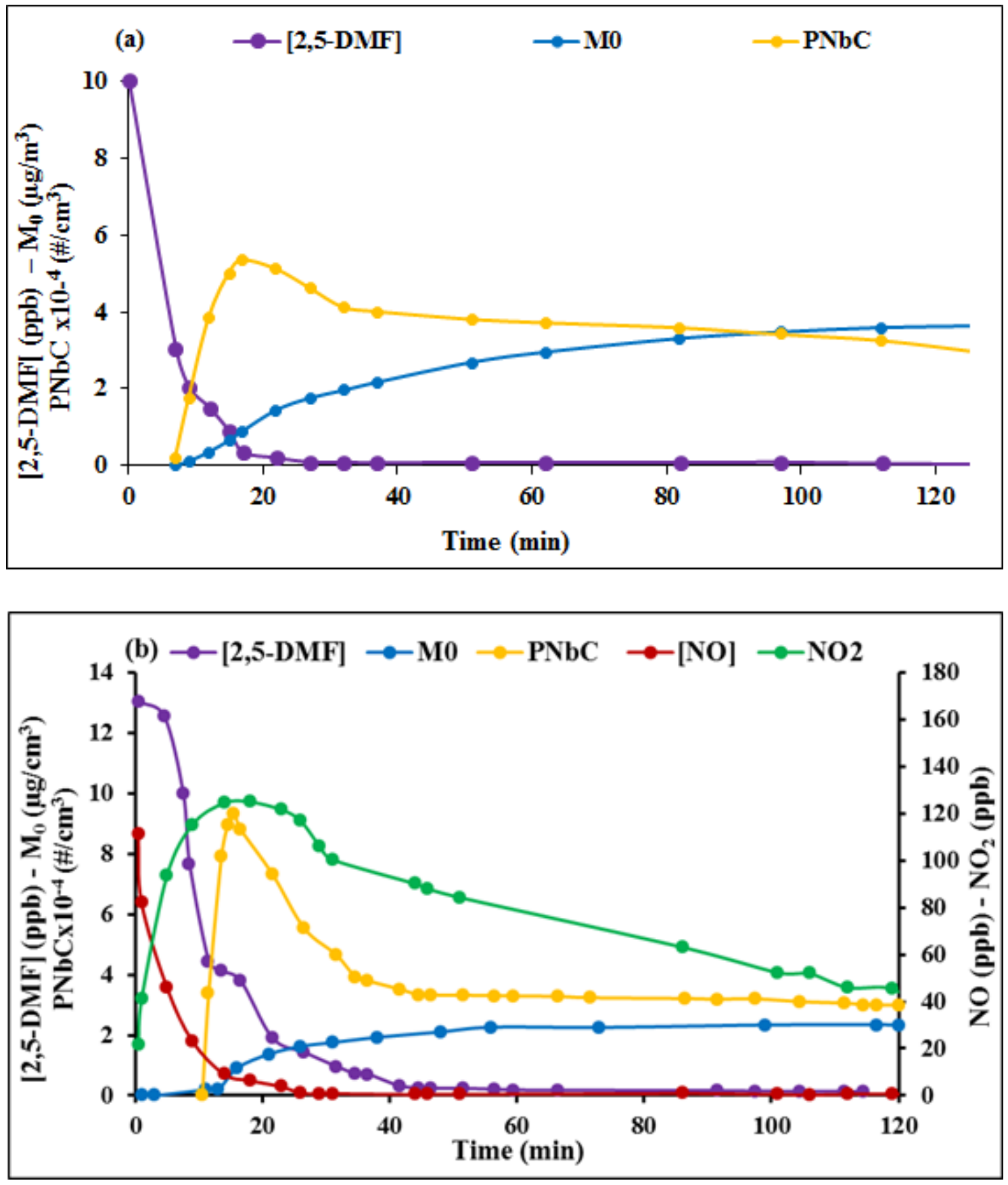

Fig. 1. Typical temporal profiles of concentrations of gas-phase reactants, SOA mass (corrected for wall-losses) and particles number concentration in absence (a) and presence (b) of NOx. In both experiments the initial concentrations were approximately $10 \mathrm{ppb}$ of 2,5-DMF and $2 \mathrm{ppm}$ of $\mathrm{H}_{2} \mathrm{O}_{2}$; and $\mathrm{RH}<6 \%$. 
As shown in Fig. 1, particle formation was not observed until $\sim$ min since the start of the reaction, with a fast increase in the particle number concentration followed by a gradual decrease after reaching a maximum at $\sim 20 \mathrm{~min}$. This observation is consistent with an initial nucleation step producing a burst of nanoparticles, followed by coagulation which results in the increase in the particle diameter, along with the corresponding decrease in the number concentration. The $\mathrm{OH}-$ 2,5-DMF photooxidation is very fast, and 2,5-DMF is consumed (from $10 \mathrm{ppb}$ to approx. $0.4 \mathrm{ppb}$ ) within the first 20 minutes of the experiment while most of SOA mass is formed well after all the organic compound has reacted. These results indicate that the initial $\mathrm{OH}-2,5-\mathrm{DMF}$ reaction itself is not the rate-limiting step in the mechanism leading to particles and there is a substantial contribution from multigenerational oxidation and/or heterogeneous/multiphase reactions to SOA formation. This same behaviour has been observed in the ozonolysis of 2,3-dihydrofuran or the $\mathrm{NO}_{3}$-oxidation of 3-methylfuran (Diaz-de-Mera et al., 2017b; Joo, 2019).

Regarding the evolution of the particle size distributions with the reaction time (see Fig. S1), particles grew up fast, reaching a final maximum diameter of around $50 \mathrm{~nm}$. Due to its size, these kinds of particles can be inhaled, penetrating into the lungs and causing serious health effects (Brown et al., 2013).

\subsubsection{Effect of 2,5-DMF concentration on SOA formation}

Experiments with RH below 6\%, no NOx added and no seed particles were carried out varying 2,5-DMF concentrations from 10 to $1000 \mathrm{ppb}$ (See Table S1). The SOA yield (Y) was determined experimentally as the ratio of the average maximum aerosol mass concentration (corrected for wall-loss) and the consumption of 2,5-DMF when $\mathrm{M}_{0}$ was measured:

$$
Y=\frac{M_{0}}{\Delta[2,5-D M F]}
$$


The uncertainties of SOA yields are $2 \sigma \pm 20 \%$ of the calculated yields for replicate experiments. As it can be seen in Fig. 2, SOA yield decreases when initial 2,5-DMF concentration increases. This result was unexpected since the typical trend is the opposite. Nevertheless, other studies have also shown similar results, such as in the 2-methylnaphthalene photooxidation and toluene and 2,3-DHF ozonolysis (Chen et al., 2016 and 2017; Diaz-de-Mera et al., 2017b). In these cases, although the experiments with high initial concentration generate more aerosol mass concentration, the SOA yields decrease. Chen et al. (2017) argued that the initial organic precursor concentrations change the oxidation pathways, which leads to different yields. Therefore, complementary studies of the SOA chemical composition at different 2,5-DMF concentrations would be needed to confirm this hypothesis.

There is no prior experimental study on SOA formation from OH-photooxidation of 2,5-DMF, except the theoretical study of Bruns et al. (2016) who found that $\mathrm{OH}$-photooxidation of the mixture of isomers of 2,4-/2,5-dimethylfuran gave a yield value close to $3 \%$. This value was estimated as the average of the published SOA yields applied to the non-methane organic gases with $\geq \mathrm{C}_{6}$ compounds. Moreover, there is a study that reported SOA formation from 2-methylfuran $+\mathrm{OH}$ reaction (Gomez-Alvarez et al., 2009), in which the SOA yield quantified in presence of $641 \mathrm{ppb}$ of precursor was $(5.5 \pm 1.6) \%$. In this work, low amounts of NOx (20.5 ppb and $45 \mathrm{ppb}$ of NO and $\mathrm{NO}_{2}$, respectively) from $\mathrm{OH}$ radical precursor (HONO) were present in the chamber; however, the NOx level was so low that the results of Gomez-Alvarez et al. could be comparable with those obtained in our study in absence of NOx. Besides, the density assumed in GomezAlvarez et al. study was slightly higher $\left(1.23 \mathrm{~g} \mathrm{~cm}^{-3}\right)$ than ours, but even considering this value, the SOA yield from 2,5-DMF is slightly lower $(1.0 \pm 0.1 \%$ at $500 \mathrm{ppb})$ than the SOA yield from 2-methylfuran, so that the presence of an additional methyl group could reduce the SOA formation. 
It should also be noted that, at low 2,5-DMF concentrations, which could be similar to those of the real atmosphere, the yield increases significantly (see Fig. 2), so this compound would be an efficient SOA precursor. In addition, losses of semivolatile vapors on chamber walls can lead to substantial underestimation of the SOA formation by factors as much as 4 (Zhang; 2014), so that SOA yields calculated in this work could be higher in real atmospheric conditions.

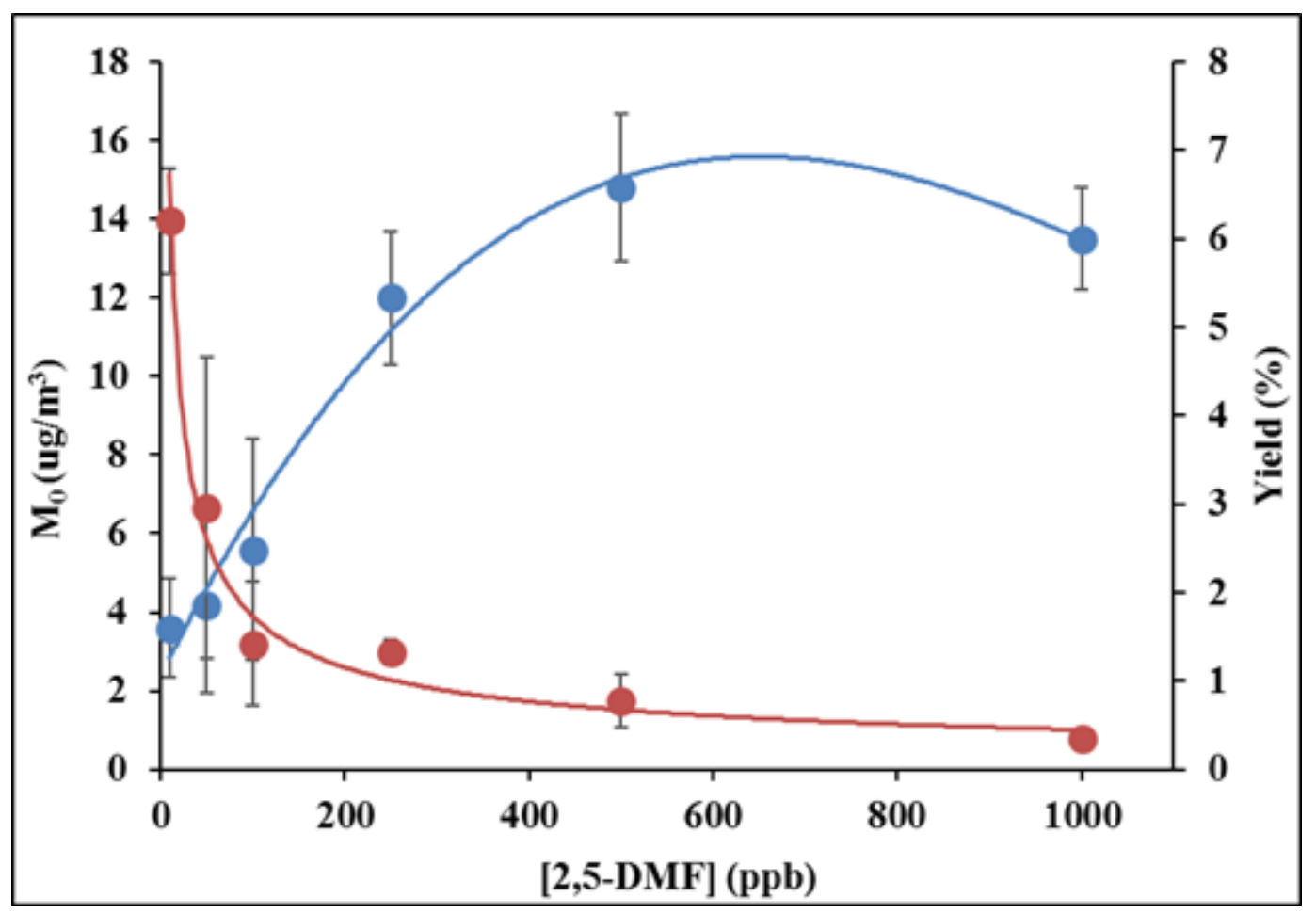

Fig. 2. SOA yield (red) and mass concentration (blue) with different initial 2,5-DMF concentrations.

\subsubsection{Effect of NOx and RH}

Experiments with different NOx concentrations and different $\mathrm{RH}$ levels were carried out in the absence of inorganic seed aerosols (see Fig. 3). 

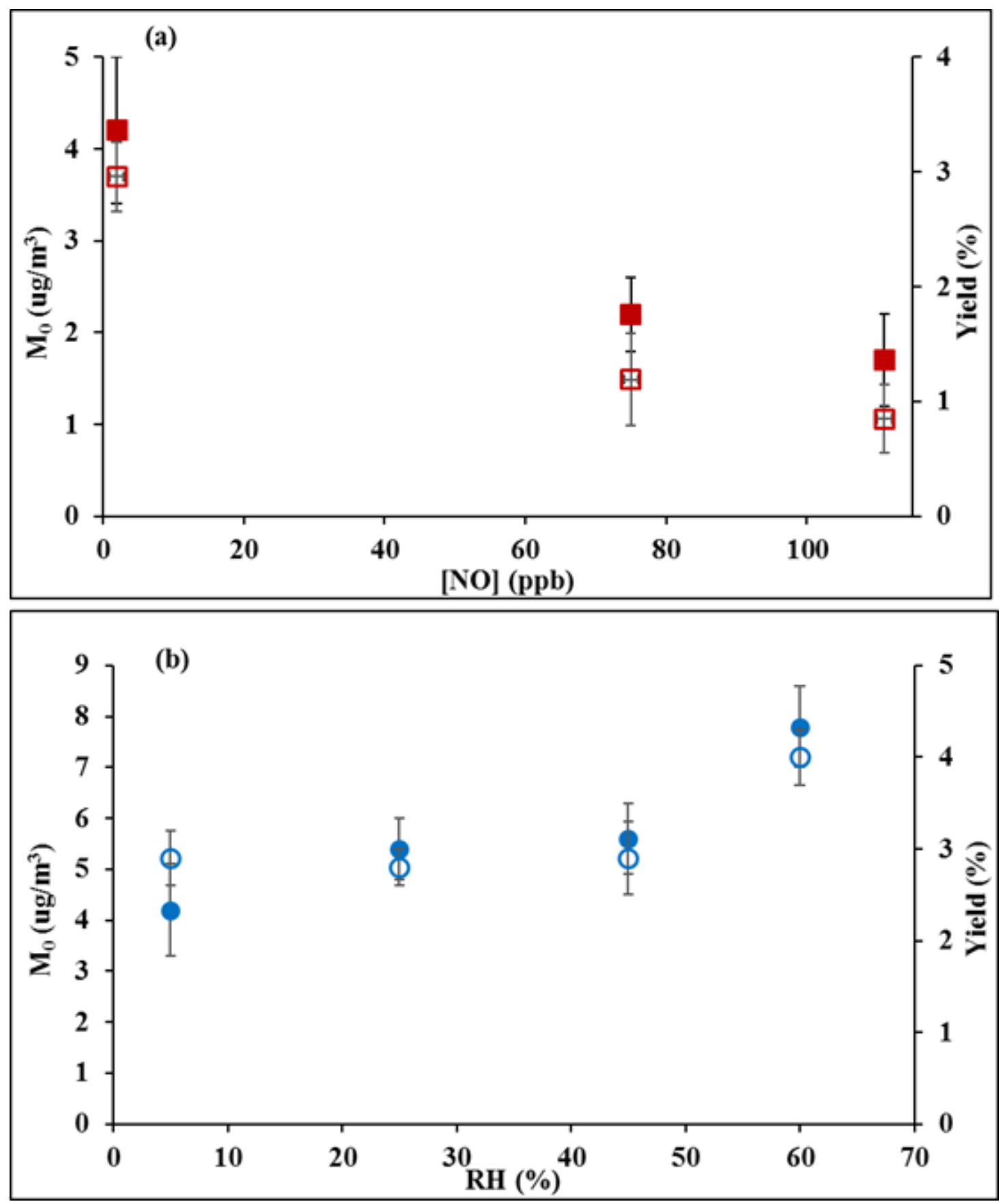

Fig. 3. SOA yield (opened symbols, right axis) and mass concentration (closed symbols, left axis) for experiments with $50 \mathrm{ppb}$ of 2,5-DMF, 2 ppm of $\mathrm{H}_{2} \mathrm{O}_{2}$ and different initial a) $\mathrm{NOx}$ and b) $\mathrm{RH}$ conditions. 
The effect of NOx level on SOA formation is very complex, and previous results about this topic have been inconclusive. Generally, the NOx level has two different effects in the reaction process. On the one hand, increasing NOx concentration will promote the $\mathrm{O}_{3}$ and $\mathrm{HONO}$ formation, leading to more $\mathrm{OH}$ radical, which in turn is favourable to SOA formation (Sarrafzadeh et al., 2016). In this study, no significant change in $\mathrm{OH}$ concentration was estimated in experiments with different NOx levels, so that this effect can be discarded. On the other hand, NOx level contributes in SOA formation by governing the reactions of organo-peroxy radicals $\left(\mathrm{RO}_{2}\right)$. $\mathrm{RO}_{2}$ are central intermediates in the VOC oxidation process. Under no NOx presence, the main sink reactions for $\mathrm{RO}_{2}$ radicals are with the hydroperoxyl radical $\left(\mathrm{HO}_{2}\right)$ and with other $\mathrm{RO}_{2}$ radicals, leading to lower-volatility products and enhancing SOA formation. However, under high NOx conditions, the primary loss process of $\mathrm{RO}_{2}$ radical is reaction with $\mathrm{NO}$ to produce alkoxy radicals (RO) or as a minor pathway, organic nitrates $\left(\mathrm{RONO}_{2}\right)$. $\mathrm{RO}$ radicals generally fragment into smaller more volatile products, resulting in small amounts of SOA (Sarrafzadeh et al., 2016). It should also be noted that the presence of sufficient seed surface area at the start of the reaction largely suppresses the effects of vapour wall losses of low-volatility compounds, including multifunctional nitrates (Schwantes et al., 2019), which promotes their partition into the particle phase and increases the SOA mass concentration (Jiang, 2019).

In the $\mathrm{OH}$-photooxidation of 2,5-DMF at low $\mathrm{RH}(<6 \%)$ and in absence of inorganic seed aerosol, SOA formation increased after NO was depleted, and the formation of first particles were delayed regarding the same experiment without NOx (See Fig. 1b). Moreover, both the mass and the yield were lower than those without NOx (See Fig. 3a). These results suggest that NOx molecules inhibit the formation of new particles and thereby limit the particle surface where low volatiles compounds can condense. Thereby, the predominant effect would be the NOx role over the fate of peroxyradicals $\left(\mathrm{RO}_{2}\right)$, which has also been observed in the $\mathrm{OH}$-photooxidation of other VOCs 
such as $\alpha$ and $\beta$-pinene, limoneno, styrene and $\alpha$-methylstyrene (Sarrafzadeh et al., 2016; Zhao et al., 2018; Tajuelo et al. 2019a, 2019b).

With regard to RH experiments, water could alter the final composition and distribution of photooxidation products through gas-phase chemistry, organic sorption of water, or by water sorption of organic products. So, RH environment contributes to the increase of the hygroscopicity of SOA. Therefore, it is expected that an increase in particulate water content would enhance SOA yields of water-miscible species (Stirnweis et al., 2017). In our experiments performed at different RH conditions, the mass concentration and the SOA yield were higher when increasing the RH in the reactor, as shown in Fig. 3b. This behaviour was also observed in the OH-photooxidation of styrene (Tajuelo et al., 2019a) and $\alpha$-methylstyrene (Tajuelo et al., 2019b). This fact can be explained by the increase in SOA formation through heterogeneous reactions and aqueous chemistry in wet aerosols (Lim et al., 2010). Hydrophilic functional groups, such as ketones and carboxylic acids, have been identified as gas-phase products in the $\mathrm{OH}$ radical-initiated reaction of 2,5-DFM (3-hexene-2,5-dione, as the main product, and additional products attributed to $\mathrm{CH}_{3} \mathrm{C}(\mathrm{O}) \mathrm{OC}\left(\mathrm{CH}_{3}\right)=\mathrm{CHCHO}$ or $\left.\mathrm{CH}_{3} \mathrm{C}(\mathrm{O}) \mathrm{CH}=\mathrm{CHC}(\mathrm{O}) \mathrm{OH}\right)$ (Aschmann, 2011; 2014). These compounds can be absorbed into the humid surface of the hygroscopic SOA at high $\mathrm{RH}$, contributing to the formation of low volatility products and increasing the SOA mass yields. Moreover, these hydrophilic functional groups at the SOA surface, could also absorb the water molecules and hence, the produced SOA could partition into new wet particles (Jiang et al., 2019).

Finally, the combined effect of NOx and RH on SOA formation was analysed (See Fig. S2). Taking into account that the rise of both parameters has the opposite effect, the mass concentration and the SOA yield are higher without NOx and high RH conditions. The second more favourable situation is no NOx added-low RH, therefore the positive effect of having lower NOx concentrations prevails over low RH conditions. 


\subsubsection{Effect of seed aerosol}

The effect of inorganic seed aerosols on the formation of SOA was investigated by comparing the SOA growth in the presence of two different sources of inorganic seed particles $\left(\mathrm{CaCl}_{2}\right.$ and $\left(\mathrm{NH}_{4}\right)_{2} \mathrm{SO}_{4}$ ). These inorganic particles are commonly present in the atmosphere (Wang et al. 2011). $\mathrm{CaCl}_{2}$ is one of the major inorganic aerosol species during dust days, while $\left(\left(\mathrm{NH}_{4}\right)_{2} \mathrm{SO}_{4}\right)$ is a major constituent during haze days (Wang et al. 2006).

To avoid the potential impacts of different variables on SOA formation, experiments without added NOx were carried out and with constant values of 2,5-DMF concentration (50 ppb) and RH ( 20\%) (See Table S1). The SOA formation is related to pre-existing particles since seed aerosols could act as the absorption or adsorption centres of SOA formation increasing its growth (Lu et al., 2009; Zhang et al., 2014).

Both $\left(\mathrm{NH}_{4}\right)_{2} \mathrm{SO}_{4}$ and $\mathrm{CaCl}_{2}$ seed aerosols enhance SOA formation and increase SOA yield (See Fig. 4). It is found that this effect is positively correlated with the seeds surface concentration and is pronounced only when this concentration reaches a threshold value. Among the two seed aerosols, $\mathrm{CaCl}_{2}$ had a higher threshold, but once this value is exceeded, the effect of this salt on the SOA mass and yield is greater, and the concentration-time profile of SOA formation for both salts was different. As it is shown in Fig. S3a, in $\left(\mathrm{NH}_{4}\right)_{2} \mathrm{SO}_{4}$ presence, SOA mass (corrected for wall-loss and the initial mass of the seed particles) was formed when all the 2,5-DMF had been consumed, indicating that the uptake of condensable particles was very slow. In this case, the secondary reactions, slower than the $\mathrm{OH}$-photooxidation of 2,5-DMF, could be the main factor in the growth of particles, contributing to the increase in SOA mass and slightly increasing their maximum diameter (see Fig. S4a). However, with $\mathrm{CaCl}_{2}$ in the medium, the uptake process into the pre-existing seed particles was faster (see Fig. S3b), and with hardly any particle growth over the reaction time (see Fig. S4b). Thereby, $\mathrm{CaCl}_{2}$ seeds would have a catalytic effect on the reaction, which could be explained by the different acidity of aerosol generated. The retention of water on the $\mathrm{CaCl}_{2}$ and $\left(\mathrm{NH}_{4}\right)_{2} \mathrm{SO}_{4}$ aerosol surface results in acidic aqueous seeds as follow: 
$\mathrm{Ca}^{2+}+\mathrm{H}_{2} \mathrm{O} \rightarrow \mathrm{Ca}(\mathrm{OH})_{2}+2 \mathrm{H}^{+}$

$\mathrm{NH}_{4}{ }^{+}+\mathrm{H}_{2} \mathrm{O} \rightarrow \mathrm{NH}_{3} \cdot \mathrm{H}_{2} \mathrm{O}+\mathrm{H}^{+}$

These acidic aqueous seeds can catalyze the heterogeneous reactions leading to the formation of high molecular weight products in particles. According to some researches, as the $\mathrm{CaCl}_{2}$ aerosol has the strongest hygroscopic behaviour among the two seed aerosols, the liquid water amount of the existing seed aerosol $\mathrm{CaCl}_{2}$ is about three times greater than within $\left(\mathrm{NH}_{4}\right)_{2} \mathrm{SO}_{4}($ Cocker et al. 2001; Huang et al., 2013, Huang et al., 2017). Thereby, the $\mathrm{CaCl}_{2}$ based aerosol has higher acidity than the aerosol generated from $\left(\mathrm{NH}_{4}\right)_{2} \mathrm{SO}_{4}$, which accelerates the process and enhances SOA. Therefore, the kind of seed particles present in the environment may affect the SOA formation due to differences in heterogeneous chemistry and water uptake, as it has been found also in previous works (Ahlberg et al., 2019). 

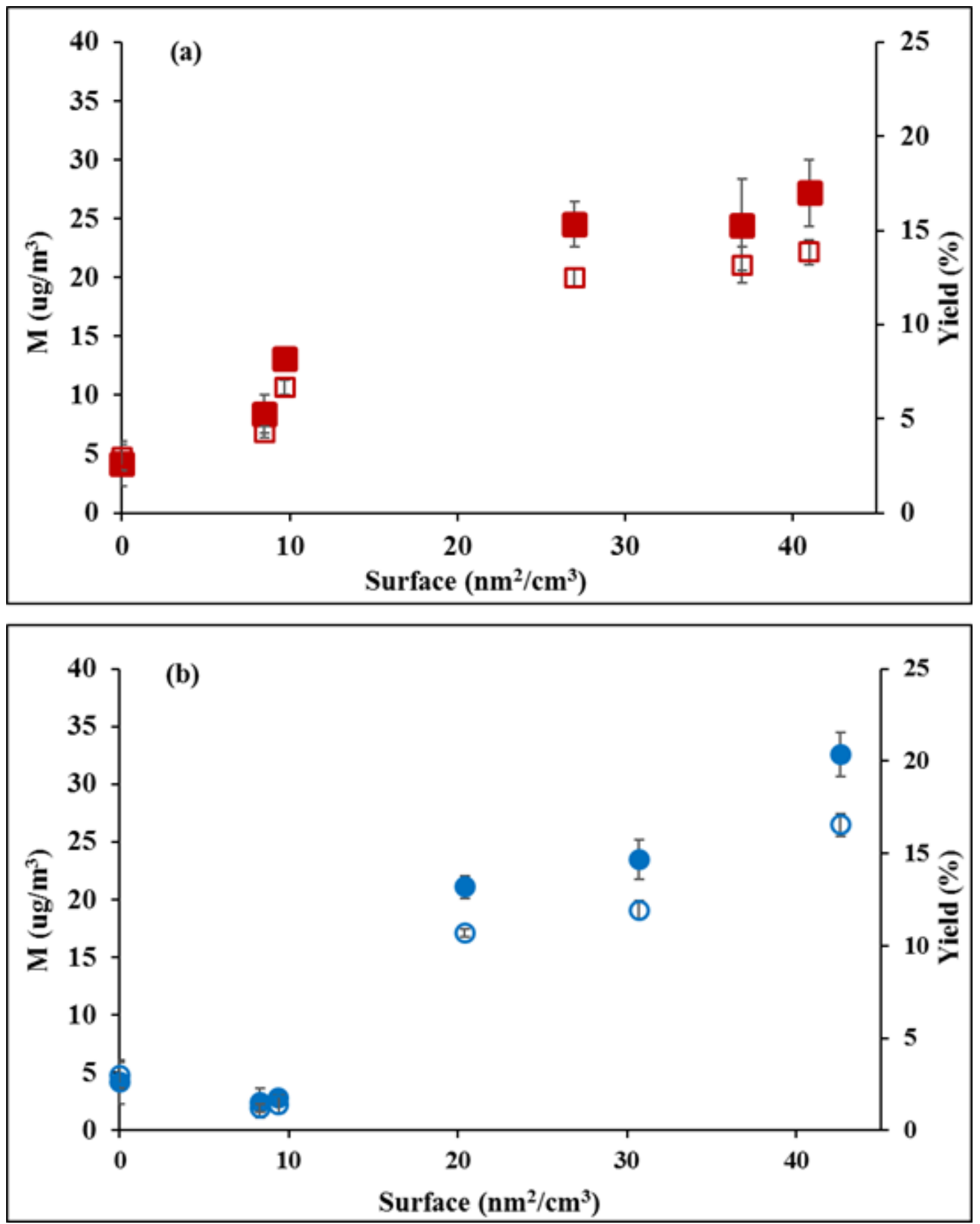

Fig. 4. SOA yield (opened symbols, right axis) and mass concentration (closed symbols, left axis) in experiments in presence of a) $\left(\mathrm{NH}_{4}\right)_{2} \mathrm{SO}_{4}$ and b) $\mathrm{CaCl}_{2}$ seed aerosols. $\mathrm{M}$ is the result of subtracting the initial inorganic seed aerosol mass from $\mathrm{M}_{0}$. 


\subsection{Ozonolysis experiments}

Different series of experiments were carried out to characterize the formation and growth of particles following the reaction of ozone with 2,5-DMF. One of this series was performed to measure the wall loss rate constant of particles. The average value was $\mathrm{k}_{\mathrm{w}}=(3.3 \pm 0.1) \times 10^{-5} \mathrm{~s}^{-1}$ and was been taken into account to obtain wall-corrected profiles from the experimental results.

\subsubsection{Nucleation conditions}

Recently, it has been found that a significant fraction of ground level sulfuric acid originates from the oxidation of sulfur dioxide by stabilised Criegee Intermediates to $\mathrm{SO}_{3}$ (Mauldin et al., 2012). This finding suggests that the presence of atmospheric traces of $\mathrm{SO}_{2}$ may enhance the production of new particles from the ozonolysis of alkenes. Furthermore, direct kinetic measurement studies have shown that Criegee intermediate reactions with $\mathrm{SO}_{2}$ are up to four orders of magnitude larger than previously thought (Khan et al., 2018b).

In this study, it was observed that the reaction of 2,5-DMF (ranging from 50 to $600 \mathrm{ppb}$ ) with ozone (in the range 70 to $1100 \mathrm{ppb}$ ) readily leads to particle formation in the presence of $\mathrm{SO}_{2}(10$ to $350 \mathrm{ppb}$ ). Nevertheless, when the reaction was followed in the absence of $\mathrm{SO}_{2}$, no particles were produced for the previous concentration ranges of reactants. So, several experiments were carried out with higher concentrations of 2,5-DMF and ozone (and without $\mathrm{SO}_{2}$ ) to force nucleation. In such experiments, from the initial concentration values of ozone and 2,5-DMF, the ozonolysis rate constant, and the reaction time when the first particles appear (more than 100

particles $\mathrm{cm}^{-3}$ ), it is possible to calculate the minimum reacted concentration of 2,5-DMF to originate nucleation, about $5 \times 10^{12}$ molecule $\mathrm{cm}^{-3}$ (200 ppb), Fig. 5. This result is approximately five times higher than in the experiments with $\mathrm{SO}_{2}$. This confirms the importance of the presence of $\mathrm{SO}_{2}$ in the formation of particles from the reaction of 2,5-DMF and ozone. Comparing this result with those obtained for other aromatic compounds like styrene $\left(1.6 \times 10^{11}\right.$ molecule $\mathrm{cm}^{-3}$, 


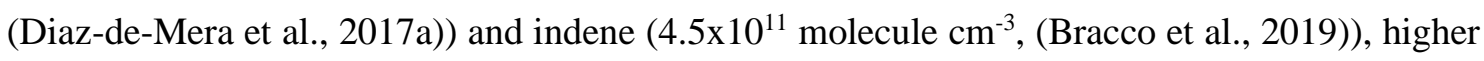
concentrations of reagents are required to form new particles from the ozonolysis of 2,5-DMF. Thus, the potential for particle formation of 2,5-DMF is lower than those of styrene or indene.

On the other hand, as stated previously, the concentration of reacted 2,5-DMF required for nucleation is significantly lower and nearly constant for $\mathrm{SO}_{2}$ concentration above $50 \mathrm{ppb}$ : (1.1 \pm 0.4$) \times 10^{12}$ molecule $\mathrm{cm}^{-3}$ (error is $2 \sigma \pm 20 \%$ ), (see Fig. 5).

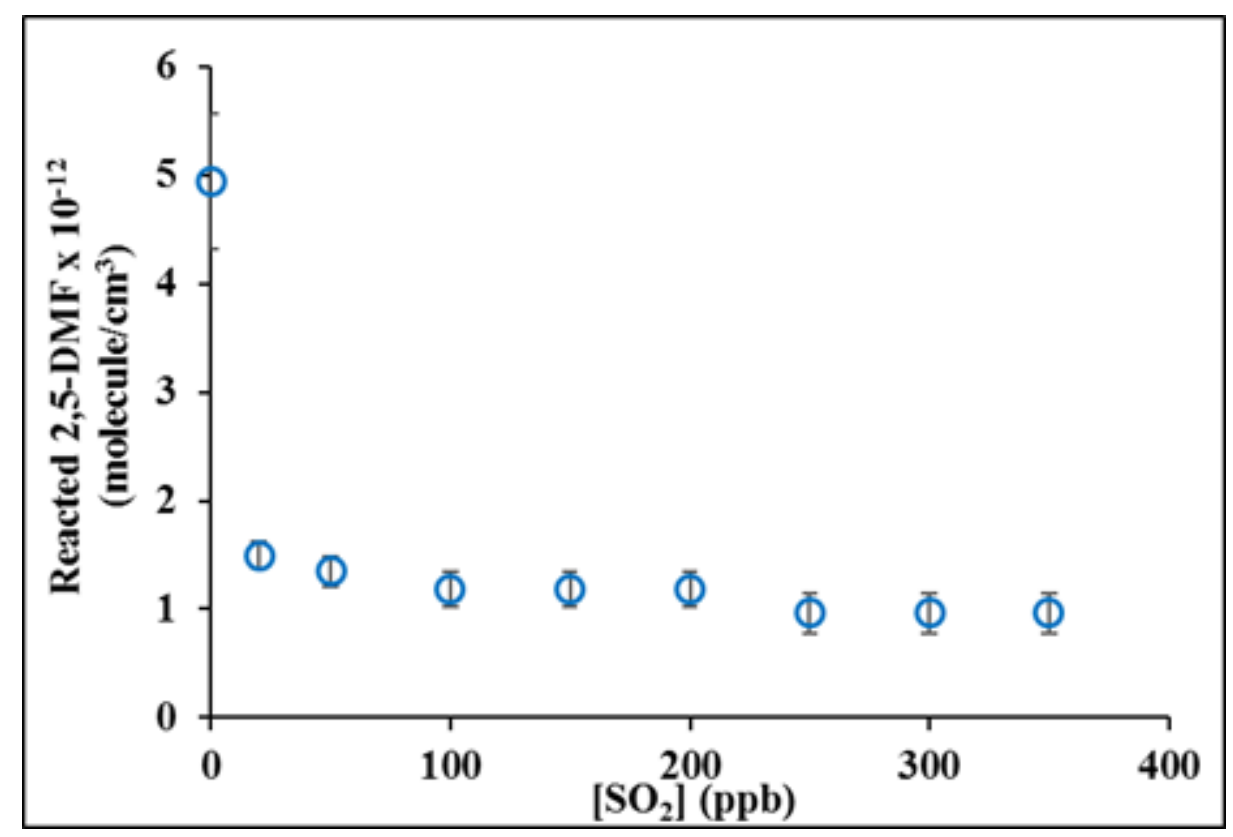

Fig. 5. Reacted 2,5-DMF concentration at the moment of nucleation (first scan when particles were detected) as a function of the $\left[\mathrm{SO}_{2}\right]$ in the ozonolysis reaction. Concentrations: 2,5-DMF (100 ppb); $\mathrm{O}_{3}(290 \mathrm{ppb}) ; \mathrm{SO}_{2}(10-350 \mathrm{ppb})$.

\subsubsection{Effect of 2,5-DMF and $\mathrm{O}_{3}$ concentration}

Different series of experiments were carried out changing the 2,5-DMF and $\mathrm{O}_{3}$ initial concentration. Thus, for example, Fig. 6a shows the results for a typical experiment with the profiles of both PNbC and Mass $\left(\mathrm{M}_{0}\right)$, as well as those simulated for 2,5-DMF, reacted 2,5-DMF and ozone. The appearance of new particles takes place approximately 5 min after the mixing of 
reactants, which leads to a delay of the mass profile with respect to the reacted concentration of 2,5-DMF. After nucleation these two profiles become similar. Such behaviour is observed under conditions where ozone is not in great excess over 2,5-DMF, and the aromatic alkene is not yet completely consumed during the experiment. These profiles suggest that ozonolysis is the limiting step in particle formation. For these experiments, a direct linear correlation is found between the aerosol mass and the mass of reacted 2.5-DMF after the nucleation event, Fig. S5, where the mass fractional yield is obtained directly from the slope of the linear correlation. 

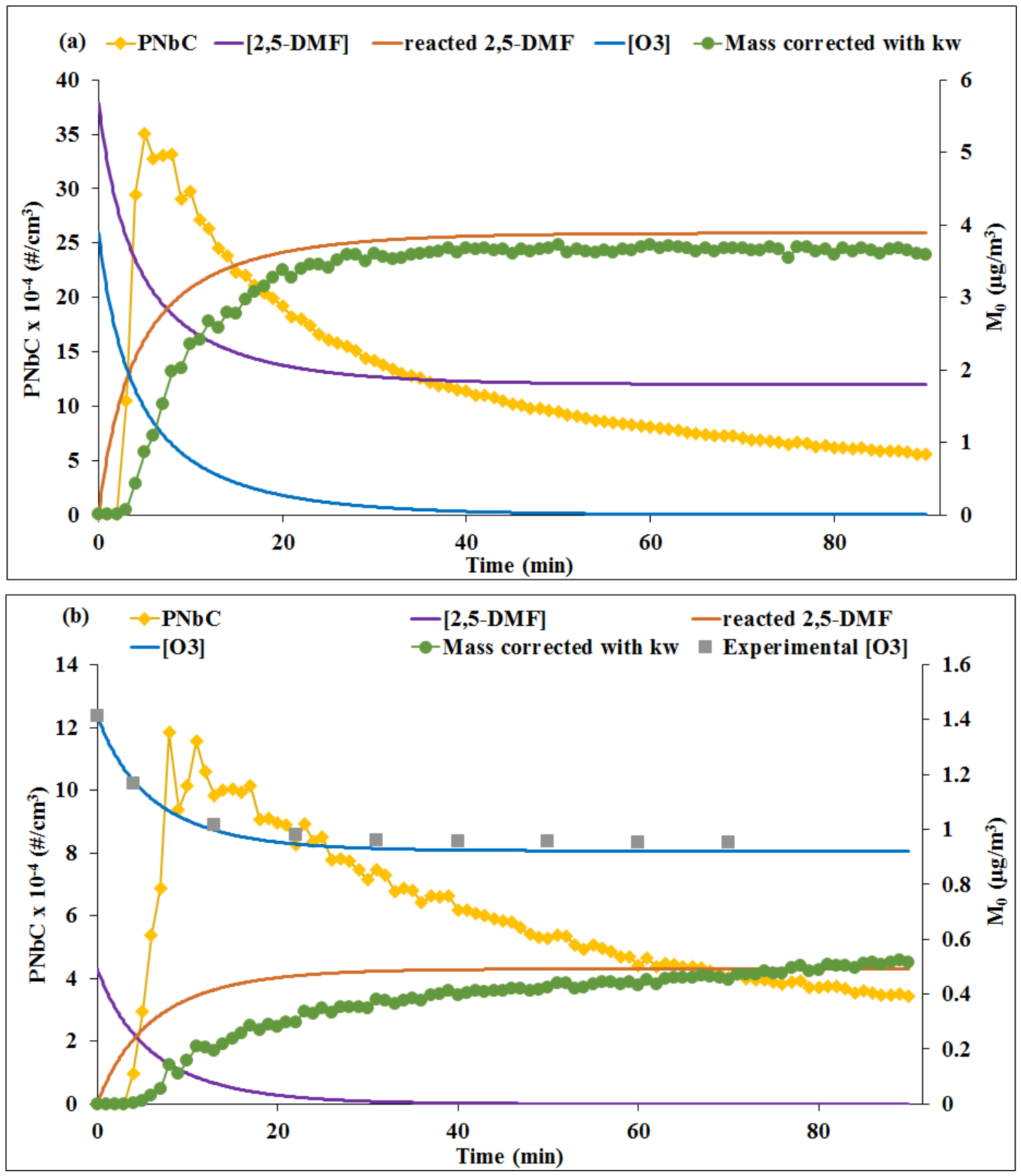

Fig. 6. Temporal profiles for 2,5-DMF, ozone, reacted 2,5-DMF, PNbC, and $\mathrm{M}_{0}$. a) Concentrations: $420 \mathrm{ppb}, 2,5-\mathrm{DMF} ; 100 \mathrm{ppb}, \mathrm{SO}_{2} ; 290 \mathrm{ppb}$, ozone; no added water. b) Concentrations: $100 \mathrm{ppb}, 2,5-\mathrm{DMF} ; 100 \mathrm{ppb}, \mathrm{SO}_{2} ; 290 \mathrm{ppb}$, ozone; no added water. In order to display all the profiles in the same figure, 2,5-DMF, reacted 2,5-DMF, ozone and experimental ozone have been multiplied for a factor. 
Fig. S6 shows the effect of increasing 2,5-DMF concentration for $\mathrm{O}_{3}$ and $\mathrm{SO}_{2}$ fixed concentrations (see also Table S1). An increase of $\mathrm{PNbC}, \mathrm{M}_{0}$, particle average diameter and fractional yield is observed. Nevertheless the maximum observed SOA fractional yield, $0.3 \%$, is significantly lower than the values observed previously for other related compound such as 2,5-dihydrofurane (2.8\%) (Diaz-de-Mera et al., 2017b) or aromatic alkenes with an exo-cyclic double bond such as styrene (39\%) (Díaz de Mera et al., 2017a). As it has been shown from both experimental and theoretical studies (Berndt et al., 2012; Vereecken et al., 2012), the ozonolysis of alkenes may lead to different yields of stabilised Criegee intermediates, depending on the initial structure of the alkene. Furthermore, the subsequent Criegee intermediate reaction with $\mathrm{SO}_{2}$ depends on the CI structure. As a result, different SOA yields are also expected from different furan derivatives with only intramolecular double bonds.

For reactions carried out under high excess of ozone, given the relatively high kinetic rate constant, $\left(\mathrm{k}=(4.2 \pm 0.9) \times 10^{-16} \mathrm{~cm}^{3}\right.$ molecule $\left.\mathrm{e}^{-1} \mathrm{~s}^{-1}\right)$ (Matsumoto, 2011) 2,5-DMF is consumed within the first few minutes. Nevertheless, the total mass of aerosol continues increasing even after the total consumption of 2,5-DMF, Fig. 6b. Thus, for such experiments, the mass fractional yield from equation (1) is not constant and rises with time.

This fact shows that secondary reactions slower than the initial step (ozonolysis of 2,5-DMF) also contribute to the growing of particles. Under such conditions, there was always a good fit between the ozone experimental profiles and the ozone profiles simulated using only the initial ozonolysis reaction (Fig. 6a), showing that secondary reactions didn't consume ozone quantitatively. On the other hand, for experiments with 2,5-DHF in excess, the profile of mass stopped growing as soon as ozone was consumed, Fig. 6 a. 
Fig. S7 and Table S1 shows the effect of rising the ozone initial concentration for fixed initial $\mathrm{SO}_{2}$ and 2,5-DMF concentrations. As shown previously, under excess of ozone, secondary reactions contribute to the growing of SOA.

Concerning the effect of $\mathrm{SO}_{2}$, as it was shown above, it enables nucleation at much lower concentrations of reacted 2,5-DMF. Furthermore, as the $\mathrm{SO}_{2}$ initial concentration increases, the total production of SOA also increases, Fig. S8. These results show that $\mathrm{SO}_{2}$ also contributes to the growing of particles. As shown in the literature (Diaz-de-Mera et al., 2017a; Diaz-de-Mera et al., 2017b; Ye et al., 2018; Zhang et al., 2019), for ozone reactions with alkenes in the presence of $\mathrm{SO}_{2}$, it is expected to react with the stabilized Criegee intermediate ( $\mathrm{sCI}$ ) obtained in the initial ozonolysis reaction of 2,5-DMF. In this sense, some experiments were conducted to assess the consumption of $\mathrm{SO}_{2}$ during the experiments. Even increasing the initial concentrations of 2,5DMF and ozone over sulphur dioxide, no changes in $\mathrm{SO}_{2}$ concentration were observed during the time of the experiments within the uncertainty limit, Fig. S9. Thus, $\mathrm{SO}_{2}$ may play a catalytic role, being released back to the gas phase. This behaviour has been found previously for other furan derivatives (Diaz-de-Mera et al., 2017b).

\subsubsection{Effect of RH}

Under atmospheric conditions, the sCI intermediate is also expected to react with water vapor molecules (Ryzhkov and Ariya, 2004). So, a series of experiments were carried out to verify if the presence of water in the reaction medium alters the production of SOA. In these experiments the $\mathrm{RH}$ was varied up to $15 \%$ keeping the concentrations of 2,5-DMF (100 ppb), $\mathrm{SO}_{2}(100 \mathrm{ppb})$, and ozone, $(290 \mathrm{ppb})$ constants. The results are shown in Fig. 7, where it is observed that as the RH increases, a decrease in the PNbC, mass, and diameter occurs. 

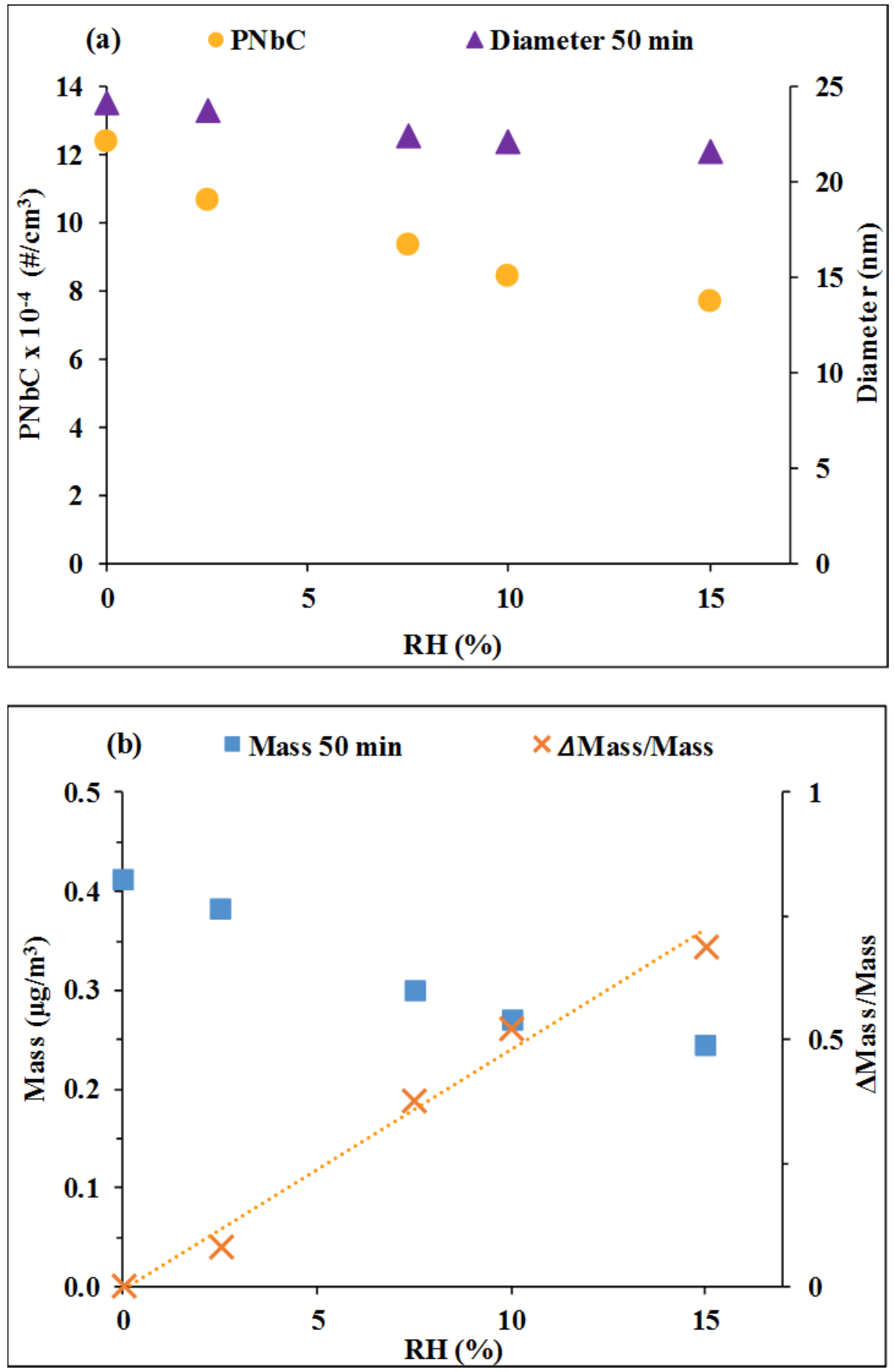

Fig. 7. Effect of water in the production of SOA. a) Maximum $\mathrm{PNbC}$ and diameter at reaction time of $50 \mathrm{~min}$. b) Mass and $\Delta$ Mass/Mass ratio at reaction time of $50 \mathrm{~min}$. Concentrations are: $[2,5-\mathrm{DMF}]=100 \mathrm{ppb} ;\left[\mathrm{SO}_{2}\right]=100 \mathrm{ppb} ;$ and $\left[\mathrm{O}_{3}\right]=290 \mathrm{ppb}$. 
Since the series of experiments was carried out in the presence of $\mathrm{SO}_{2}$, this decrease in the formation of $\mathrm{SOA}$ may be due to the competition of $\mathrm{SO}_{2}$ and water for the Criegee intermediate. As it has been described in previous studies (Vereeken et al., 2012; Bracco et al.,2019), sCI reacts with $\mathrm{SO}_{2}$ to form an intermediate cyclic secondary ozonide which subsequently decomposes to products. On the other hand, the sCI-water reaction proceeds through the addition of the water oxygen atom to the $\mathrm{C}$-atom in the carbonyl oxide and the transfer of one $\mathrm{H}$ - atom from the water molecule to the terminal oxygen atom in the Criegee intermediate. This competition can make one reaction or another more favoured, depending on the concentrations present in the medium, and the values of the respective constants, $\mathrm{k}_{\mathrm{SO} 2}$ and $\mathrm{k}_{\mathrm{H} 2 \mathrm{O}}$.

In the absence of $\mathrm{SO}_{2}$, the formation of new particles was not observed for ozonolysis of 2,5DMF under the range of RH studied in this work. Thus, we may assume that the total mass of aerosol, Mass, comes exclusively from the $\mathrm{sCI}-\mathrm{SO}_{2}$ reaction. So, if we compare experiments in the absence and presence of water, for a given experiment the decrease in mass concentration with respect to the dry conditions, $\Delta$ Mass $=$ Mass ${ }_{\mathrm{RH}}=0-$ Mass, is attributable to the reaction of the sCI with water molecules and so it depends on the product $\mathrm{k}_{\mathrm{H} 2 \mathrm{O}}\left[\mathrm{H}_{2} \mathrm{O}\right]$. Likewise, the current mass value is attributable to the $\mathrm{SCI}-\mathrm{SO}_{2}$ reaction and depends on the product $\mathrm{k}_{\mathrm{SO}_{2}}\left[\mathrm{SO}_{2}\right]$. Thus, the ratio $\left(\mathrm{k}_{\mathrm{H} 2 \mathrm{O}}\left[\mathrm{H}_{2} \mathrm{O}\right]\right) /\left(\mathrm{k}_{\mathrm{SO}_{2}}\left[\mathrm{SO}_{2}\right]\right)$ can be obtained as the ratio $\Delta$ Mass/Mass and the plot ( $\Delta$ Mass/Mass) versus $\left[\mathrm{H}_{2} \mathrm{O}\right]$, Fig. $7 \mathrm{~b}$, provides the $\left(\mathrm{k}_{\mathrm{H} 2 \mathrm{O}} /\left(\mathrm{k}_{\mathrm{SO} 2}\left[\mathrm{SO}_{2}\right]\right)\right)$ ratio from the slope. Given the $\mathrm{SO}_{2}$ concentration for this series of experiments $(100 \mathrm{ppb})$, the constants ratio is obtained, $\mathrm{k}_{\mathrm{H} 2 \mathrm{O}} / \mathrm{k}_{\mathrm{SO} 2}=(1.6 \pm 0.4) \times 10^{-5}$ (error is $\left.2 \sigma \pm 20 \%\right)$.

This constant ratio $\left(\mathrm{k}_{\mathrm{H} 2 \mathrm{O}} / \mathrm{k}_{\mathrm{SO} 2}\right)$ has also been determined for other compounds with similar structure such as 2,3-DHF and 2,5-DHF (Diaz-de-Mera et al., 2017b). For the first case, the value obtained $\left((9.8 \pm 3.7) \times 10^{-5}\right)$ was significantly higher (although of the same order) than the obtained 
in this work. On the other hand, for 2,5-DHF the contribution of the reaction with water was negligible. It is thus shown that both the position of the double bond within the cycle, and the type of substituent have a significant effect on the constant ratio for these reactions. Considering the literature data, the obtained constants ratio is similar to other reported values for different sCI (Berndt et al., 2014) and styrene (2.8 \pm 0.7$) \times 10^{-5}$, (Diaz-de-Mera et al., 2017a) or indene $(2.0 \pm 0.8) \times 10^{-5}$ (Bracco et al., 2019).

The result obtained in this work for $\left(\mathrm{k}_{\mathrm{H} 2 \mathrm{O}} / \mathrm{k}_{\mathrm{SO} 2}\right)$ may be used to assess different atmospheric conditions. For example, for 30\% RH in urban relatively polluted atmospheres like in Madrid (Spain), with $\mathrm{SO}_{2}$ concentrations around $10 \mu \mathrm{g} / \mathrm{m}^{3}$ (MITECO, 2020), approximately 3\% of the sCI produced in the ozonolysis of 2,5-DMF would react with $\mathrm{SO}_{2}$, contributing to nucleation events or to the growing of pre-existing particles. For $10 \% \mathrm{RH}$, the value would rise up to $9 \%$. Although the $\mathrm{SO}_{2}$ reaction pathway is not quantitative, in the lower troposphere, other pollutants would be simultaneously producing condensable products. Since nucleation under real atmospheric conditions is due to the cumulative sources of non-volatile species, these events are expected to generate under lower concentrations than those found in the laboratory for the isolated sources. On the other hand, for remote non polluted sites, with $\mathrm{SO}_{2}$ levels below $1 \mu \mathrm{g} / \mathrm{m}^{3}$ and $30 \%$ $\mathrm{RH}$, a very small ratio of the $\mathrm{sCI}(<0.4 \%)$ would react with $\mathrm{SO}_{2}$ and so the ozonolysis of $2,5-$ DMF is expected to hardly contribute to nucleation events under such conditions.

\section{Conclusions and atmospheric implications}

In this study, we investigated the SOA produced from both 2,5-DMF OH-photooxidation and ozonolysis and the role of NOx, $\mathrm{RH}$ and seed aerosols on the photooxidation, and $\mathrm{SO}_{2}$ and $\mathrm{RH}$ on the ozonolysis process. This approach provides detailed daytime chemistry about SOA formation from 2,5-DMF oxidation and improves our understanding of the chemical evolution of biomass burning plumes. 
Experimental results showed that in both processes, half of the SOA mass is generated once 2,5DMF has been completely consumed, highlighting the importance of higher-generation or multiphase reactions to aerosol formation. In the real atmosphere, under usual $\mathrm{SO}_{2}$ levels below $10 \mathrm{ppb}$ and RH above 30\%, SOA production by ozonolysis must be minor. However, under such humidity conditions or even with higher, $\mathrm{OH}$-photooxidation would lead more effectively to SOA formation through heterogeneous reactions and aqueous chemistry in hygroscopic aerosols. Moreover, the formation of new particles and its growth would be even higher in environments with low NOx concentrations and the presence of inorganic seed aerosols, although the effect of each type of seed aerosol could depend on its heterogeneous chemistry and its water absorption. These results confirm the potential interactions between biogenic or biomass burning emissions and anthropogenic emissions in urban areas (Zhao et al., 2018). Nevertheless, further studies are required to analyse the chemical composition of the particle phase from 2,5-DMF OHphotooxidation and ozonolysis, in order to better assess the role of this organic compound in the atmospheric SOA formation.

Finally, this study and additional works covering complementary conditions could help improve the capacity to predict the impacts of biomass burning emissions globally. Moreover, SOA formation could be integrated into air quality simulation models, especially in developing countries which are suffering severe fine particulate matter pollution.

\section{Acknowledgments}

The authors gratefully acknowledge financial support from Spanish Ministerio de Ciencia, Innovación y Universidades, Reference RTI2018-099503-B-I00 and by Junta de Comunidades de Castilla-La Mancha, Reference SBPLY/17/180501/000522.

\section{References}


Ahlberg, E., Eriksson, A., Brune, W. H., Roldin, P., Svenningsson, B., 2019. Effect of salt seed particle surface area, composition and phase on secondary organic aerosol mass yields in oxidation flow reactors. Atmos. Chem. Phys., 19, 2701-2712. https://doi.org/10.5194/acp-192701-2019

Andreae, M. O., 2019. Emission of trace gases and aerosols from biomass burning - an updated assessment. Atmos. Chem. Phys. 19, 8523-8546. https://doi.org/10.5194/acp-19-8523-2019

Aranda, A., Diaz-de-Mera, Y., Notario, A., Rodriguez, D., Rodríguez, A., 2015. Fine and ultrafine particles in small cities. A case study in the south of Europe. Environ Sci. Pollut Res. .22, 18477-18486. https://doi.org/10.1007/s11356-015-5165-4

Aschmann, S. M., Nishino, N., Arey, J., Atkinson, R., 2011. Kinetics of the Reactions of OH Radicals with 2- and 3-Methylfuran, 2,3- and 2,5-Dimethylfuran, and E- and Z-3-Hexene-2,5dione, and Products of $\mathrm{OH}+$ 2,5-Dimethylfuran. Environ. Sci. Technol. 45, 1859-1865. https://doi.org/10.1021/es103207k

Aschmann, S. M., Nishino, N., Arey, J., Atkinson, R., 2014. Products of the OH radical-initiated reactions of furan, 2- and 3-methylfuran, and 2,3- and 2,5-dimethylfuran in the presence of NO. J Phys Chem A 118, 457-466. https://doi.org/10.1021/jp410345k

Berndt, T., Jokinen, T., Mauldin, R. L., Petaja, T., Herrmann, H, Junninen, H., Passonen, P., Worsnop, D. R., Sipila, M., 2012. Gas-Phase ozonolysis of Selected olefins: The yield of stabilized criegee Intermediate and the reeactivity toward $\mathrm{SO}_{2}$. J. Phys. Chem. Lett. 3, 2892-2896. https://doi.org/10.1021/jz301158u

Berndt, T, Jokinen, T., Sipilä, M., Mauldin, R. L, Herrmann, H., Stratmann, F., Junninen, H., Kulmala, M., 2014. $\mathrm{H}_{2} \mathrm{SO}_{4}$ formation from the gas-phase reaction of stabilized Criegee 
Intermediates with $\mathrm{SO}_{2}$ : Influence of water vapour content and temperature. Atmos. Environ. 89, 603-612. https://doi.org/10.1016/j.atmosenv.2014.02.062

Bond, T. C., Doherty, S. J., Fahey, D. W., Forster, P. M., Berntsen, T., DeAngelo, B. J., Flanner, M- G., Ghan, S., Kärcher, B., Koch, D., Kinne, S., Kondo, Y., Quinn, P. K., Sarofim, M. C., Schultz, M. G., Schulz, M., Venkataraman, C., Zhang, H., Zhang, S., Bellouin, N., Guttikunda, S. K., Hopke, P. K., Jacobson, M. Z., Kaiser, J. W., Klimont, Z.,. Lohmann, U., Schwarz, J. P., Shindell, D., Storelvmo, T., Warren, S. G., Zender, C. S., 2013. Bounding the role of black carbon in the climate system: A scientific assessment. J. Geophys. Res. Atmos. 118, 5380-5552. https://doi.org//10.1002/jgrd.50171

Bracco, L. L. B., Tucceri, M. E., Escalona, A., Diaz-de-Mera, Y., Aranda, A., Rodriguez, A. M., Rodriguez, D., 2019. New particle formation from the reactions of ozone with indene and styrene. Phys. Chem. Chem. Phys. 21, 11214-11222. https://doi.org/ 10.1039/c9cp00912d

Brown, J. S., Gordon, T., Price, O., Asgharian, B., 2013. Thoracic and respirable particle definitions for human health risk assessment. Part Fibre Toxicol. 10:12. https://doi.org/10.1186/1743-8977-10-12

Bruns, E., El Haddad, I., Slowik, J., Kilic, D., Klein, F., 2016. Identification of significant precursor gases of secondary organic aerosols from residential wood combustion. Sci Rep. 6: 27881. https://doi.org/10.1038/srep27881

Chen, C-L., Kacarab, M., Tang, P., Cocker III, D. R., 2016. SOA formation from naphthalene, 1methylnaphthalene, and 2-methylnaphthalene photooxidation. Atmos. Environ. 131, 424-433. https://doi.org/10.1016/j.atmosenv.2016.02.007

Chen, L., Bao, K., Li, K., Lv, B., Bao, Z., Lin, C., Wu, X., Zheng, C., Gao, X., Cen, K., 2017. Ozone and Secondary Organic Aerosol Formation of Toluene/NOx Irradiations under Complex 
Pollution Scenarios. Aerosol Air Qual. Res. 17, 1760-1771. https://doi.org/10.4209/aaqr.2017.05.0179

Chidambaram, M., Bell A. T., 2010. A two-step approach for the catalytic conversion of glucose to 2,5-dimethylfuran in ionic liquids. Roy Soc Chem. 12, 1253-1262. https://doi.org/10.1039/C004343E

Cocker III, D. R., Mader, B. T., Kalberer, M., Flagan, R. C., Seinfeld. J. H., 2001. The effect of water on gas-particle partitioning of secondary organic aerosol: II. m-xylene and 1,3,5trimethylbenzene photooxidation systems. Atmos. Environ. 35, 6073-6085. https://doi.org/10.1016/S1352-2310(01)00405-8

De Meyer, A., Cattrysse, D., Rasinmäki, J., Van Orshoven, J., 2014. Methods to optimise the design and management of biomass-for-bioenergy supply chains: A review. Renew. Sust. Energ. Rev. 31, 657-670. https://doi.org/10.1016/j.rser.2013.12.036

Daniel, R., Tian, G., Xu, H., Shuai, S. 2012. Ignition timing sensitivities of oxygenated biofuels compared to gasoline in a direct-injection SI engine Fuel 99, 72-82. https://doi.org/10.1016/j.fuel.2012.01.053

Diaz-de-Mera, Y., Aranda, A., Martinez, E., Rodriguez, A. A., Rodriguez, D., Rodriguez, A., 2017a. Formation of secondary aerosols from the ozonolysis of styrene: Effect of $\mathrm{SO}_{2}$ and $\mathrm{H}_{2} \mathrm{O}$. Atmos. Environ. 171, 25-31. http://dx.doi.org/10.1016/j.atmosenv.2017.10.011

Diaz-de-Mera, Y., Aranda A., Bracco, L., Rodriguez, D., Rodríguez, A., 2017b. Formation of secondary organic aerosols from the ozonolysis of dihydrofurans. Atmos. Chem. Phys. 17, 23472357. https://doi.org/10.5194/acp-17-2347-2017 
Giele, D., Boshell, F., Saygin, D., Bazilian, M. D., Wagner, N. Gorini, R., 2019. The role of renewable energy in the global energy transformation. Energy Strategy Rev. 24, 38-50. https://doi.org/10.1016/j.esr.2019.01.006

Gomez-Alvarez, E. G.; Borrás, E.; Viidanoja, J.; Hjorth, J., 2009. Unsaturated dicarbonyl products from the $\mathrm{OH}$-initiated photooxidation of furan, 2-methylfuran and 3-methylfuran. Atmos. Environ. 43, 1603-1612. https://doi.org/10.1016/j.atmosenv.2008.12.019

Graziani, M., Fornasiero, P., 2007. Renewable resources and renewable energy: a global challenge. Boca Raton, F.L. CRS Press, Taylor and Francis Group.

Hein, R., Crutzen, P.J., Heimann, M., 1997. An inverse modeling approach to investigate the global atmospheric methane cycle. Global Biogeochem. Cycles. 11, 43-76 https://doi.org/10.1029/96GB03043

Huang, M., Hao, L., Gu, X., Hu, C., Zhao, W., Wang, Z., Fang, L., Zhang, W., 2013. Effects of inorganic seed aerosols on the growth and chemical composition of secondary organic aerosol formed from OH-initiated oxidation of toluene. J Atmos Chem. 70, 151-164. https://doi.org/110.1007/s10874-013-9262-9

Huang, M., Xu, J., Cai, S., Liu, X., Hu, C., Gu, X., Fang, L., Zhang, W., 2017. Mass Spectral analysis of the aged 1,3,5-trimethylbenzene secondary organic aerosol in the presence of ammonium sulfate seeds. Pol. J. Environ. Stud. 26, 1531-1537. https://doi.org/10.15244/pjoes/66768

Isikgor, F. H., Becer, C.R., 2015. Lignocellulosic biomass: a sustainable platform for the production of bio-based chemicals and polymers. Polym. Chem. 6, 4497-4559. https://doi.org/10.1039/c5py00263j 
Jiang, X., Tsona, N. T., Jia, L., Liu, S., Xu, Y., Du, L, 2019. Secondary organic aerosol formation from photooxidation of furan: effects of NOx level and humidity. Atmos. Chem. Phys. Discuss. 19, 13591-13609. https://doi.org/10.5194/acp-19-13591-2019

Jimenez J. L., M. R. Canagaratna, N. M. Donahue, A. S. H. Prevot, Q. Zhang, J. H. Kroll, P. F. DeCarlo, J. D. Allan, H. Coe, N. L. Ng, A. C. Aiken, K. S. Docherty, I. M. Ulbrich, A. P. Grieshop, A. L. Robinson, J. Duplissy, J. D. Smith, K. R. Wilson, V. A. Lanz, C. Hueglin, Y. L. Sun, J. Tian, A. Laaksonen, T. Raatikainen, J. Rautiainen, P. Vaattovaara, M. Ehn, M. Kulmala, J. M. Tomlinson, D. R. Collins, M. J. Cubison, E., J. Dunlea, J. A. Huffman, T. B. Onasch, M. R. Alfarra, P. I. Williams, K. Bower, Y. Kondo, J. Schneider, F. Drewnick, S. Borrmann, S. Weimer, K. Demerjian, D. Salcedo, L. Cottrell, R. Griffin, A. Takami, T. Miyoshi, S. Hatakeyama, A. Shimono, J. Y Sun, Y. M. Zhang, K. Dzepina, J. R. Kimmel, D. Sueper, J. T. Jayne, S. C. Herndon, A. M. Trimborn, L. R. Williams, E. C. Wood, A. M. Middlebrook, C. E. Kolb, U. Baltensperger, Worsnop., D. R., 2009. Evolution of organic aerosols in the atmosphere. Science. 326, 1525-1529 https://doi.org/10.1126/science.1180353

Joo, T., Rivera-Rios, J., Takeuchi, M., Alvarado, M. J., Ng, N. L., 2019. Secondary Organic Aerosol Formation from Reaction of 3-Methylfuran with Nitrate Radicals. ACS Earth Space Chem. 3, 922-934. https://doi.org/10.1021/acsearthspacechem.9b00068

Khan, M. I., Shin J. H., Kim J. D., 2018. The promising future of microalgae: current status, challenges, and optimization of a sustainable and renewable industry for biofuels, feed, and other products. Microb Cell Fact. 17: 36. https://doi.org/10.1186/s12934-018-0879-x

Khan, M. A. H., Percival, C. J., Caravan, R. L., Taatjes, C. A., Shallcross, D. E., 2018b. Criegee intermediates and their impacts on the troposphere. Environ. Sci.: Processes Impacts, 20, 437453. https://doi.org/10.1039/c7em00585g 
Lee, J., Park, K.Y., 2020. Impact of hydrothermal pretreatment on anaerobic digestion efficiency for lignocellulosic biomass: Influence of pretreatment temperature on the formation of biomass-

$\begin{array}{llll}\text { degrading } & \text { byproducts. } & \text { Chemosphere. } & 25116 .\end{array}$ https://doi.org/10.1016/j.chemosphere.2020.127116

Lim, Y. B., Tan, Y., Perri, M. J., Seitzinger, S. P., Turpin, B. J., 2010. Aqueous chemistry and its role in secondary organic aerosol (SOA) formation. Atmos. Chem. Phys. 10, 10521-10539. https://doi.org/10.5194/acp-10-10521-2010

Logan, J. A., 1985. Tropospheric ozone: Seasonal behavior, trends, and anthropogenic influence. J. Geophys. Res. 90, 10463-10482. https://doi.org/10.1029/JD090iD06p10463.

Lu, Z., Jao, J., Takekawa, H., Hu, L., Li, J., 2009. Effect of high concentrations of inorganic seed aerosols on secondary organic aerosol formation in the m-xylene/NOx photooxidation system. Atmos. Environ. 43, 897-904. https://doi.org/10.1016/j.atmosenv.2008.10.047

Luque, R., Herrero-Davila, L., Campelo, J. M, Clark, J. H, Hidalgo, J. M, Luna, D., Marinas, J. M., Romero, A., 2008. A. Biofuels: a technological perspective. Energy Environ Sci 1, 513-93. https://doi.org/110.1039/B807094F

Mascal, M., Nikitin, E. B., 2008. Direct, high-yield conversion of cellulose into biofuel. Angew. Chem., Int. Ed. Engl. 47, 7924-7926. https://doi.org/10.1002/ange.200801594

Matsumoto, J., 2011. Kinetics of the Reactions of Ozone with 2,5-Dimethylfuran and its Atmospheric Implications. Chem. Lett. 40, 582-583. https://doi.org/10.1246/cl.2011.582

Mauldin, R. L., Berndt, T., Sipilä, M., Paasonen, P., Petäjä, T., Kim, S., Kurtén, T., Stratmann, F., Kerminen, V. M.,Kulmala, M. 2012. A new atmospherically relevant oxidant of sulphur dioxide, Nature, 488, 193-196. https://doi.org/10.1038/nature11278 
MITECO, 2020. National inventory, air quality database. https://www.miteco.gob.es/es/calidady-evaluacion-ambiental/temas/atmosfera-y-calidad-del-aire/calidad-del-aire/evaluaciondatos/datos/Default.aspx

Nah, T., McVay, R.C., Pierce, J.R., Seinfeld, J.H., Ng, N.L., 2017. Constraining uncertainties in particle-wall deposition correction during SOA formation in chamber experiments. Atmos. Chem. Phys. 17, 2297e2310. https://doi.org/10.5194/acp-17-2297-2017.

Pérez Pastor, R., Salvador, P. García Alonso, S., Alastuey, A., García dos Santos, S., Querol, X., Artíñano, B. 2020. Characterization of organic aerosol at a rural site influenced by olive waste

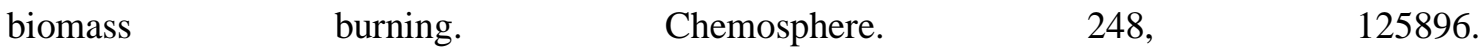
https://doi.org/10.1016/j.chemosphere.2020.125896

Ren, J. Y., Zhang, F., Wang, Y. Y., Collins, D., Fan, X. X., Jin, X. A., Xu, W. Q., Sun, Y. L., Cribb, M., Li, Z. Q., 2018. Using different assumptions of aerosol mixing state and chemical composition to predict $\mathrm{CCN}$ concentrations based on field measurements in urban Beijing. Atmos. Chem. Phys. 18, 6907-6921, https://doi.org/10.5194/acp-18-6907-2018

Requia, W. J., Higgins, C. D., Adams, M. D., Mohamed, M., Koutrakis, P., 2018. The health impacts of weekday traffic: A health risk assessment of $\mathrm{PM}_{2.5}$ emissions during congested periods. Environ. Int. 111, 164-176. https://doi.org/10.1016/j.envint.2017.11.025

Roman-Leshkov R., Barrett, C. J., Liu, Z. Y. Dumesic, J. A., 2007. Production of dimethylfuran for liquid fuels from biomass-derived carbohydrates. Nature. 447, 982-985. https://doi.org/10.1038/nature05923

Ryzhkov, B., Ariya, P. A., 2004. A theoretical study of the reactions of parent and substituted Criegee intermediates with water and the water dimer. Phys. Chem. Chem. Phys. 6, 5042-5050. https://doi.org/10.1039/B408414D 
Sarrafzadeh, M., Wildt, J., Pullinen, I., Springer, M., Kleist, E., Tillmann, R., Schmitt, S. H., Wu, C., Mentel, T. F., Zhao, D., Hastie, D. R., Kiendler-Scharr, A., 2016. Impact of NOx and OH on secondary organic aerosol formation from $\beta$-pinene photooxidation. Atmos. Chem. Phys. 16, 11237-11248. https://doi.org/10.5194/acp-16-11237-2016.

Schwantes, R. H., Charan, S. M., Bates, K. H., Huang, Y., Nguyen, T. B., Mai, H., Kong, W., Flagan, R. C., Seinfeld, J. H., 2019. Low-volatility compounds contribute significantly to isoprene secondary organic aerosol (SOA) under high-NOx conditions. Atmos. Chem. Phys. 19, 7255-7278. https://doi.org/10.5194/acp19-7255-2019

Scott C. E., Spracklen, D.V., Forster, P. M., Carslaw, K. S., Mann, G. W. Pringle, K. J, Kivekäs, N., Kulmala, M., Lihavainen, H., Tunved, P., 2014. The direct and indirect radiative effects of biogenic secondary organic aerosol. Atmos. Chem. Phys. 14, 447-470. doi.org/10.5194/acp-14$447-2014$

Shrivastava, M., Easter, R. C., Liu, X., Zelenyuk, A., Singh, B., Zhang, K., Ma, P-L., Chand, D., Ghan, S., Jimenez, J. L., Zhang, Q., Fast, J., Rasch, P. J., Tiitta, P., 2015. Global transformation and fate of SOA: Implications of low-volatility SOA and gas-phase fragmentation reactions, J. Geophys. Res. Atmos. 120, 4169-4195. https://doi.org/10.1002/2014JD022563

Spracklen, D. V., Jimenez, J. L., Carslaw, K. S., Worsnop, D. R., Evans, M. J., Mann, G. W., Zhang, Q., Canagaratna, M. R., Allan, J., Coe, H., McFiggans, G., Rap, A., Forste, P., 2011. Aerosol mass spectrometer constraint on the global secondary organic aerosol budget. Atmos. Chem. Phys. 11, 12109-12136. https://doi.org//10.5194/acp-11-12109-2011

Stirnweis, L., Marcolli, C., Dommen, J., Barmet, P., Frege, C., Platt, S. M., Bruns, E. A., Krapf, M, Slowik, J. G, Wolf, R., Prévôt, A. S. H., Baltensperger, U., El-Haddad, I., 2017. Assessing the influence of NOx concentrations and relative humidity on secondary organic aerosol yields 
from $\alpha$-pinene photooxidation through smog chamber experiments and modelling calculations. Atmos. Chem. Phys. 17, 5035-5061. https://doi.org/10.5194/acp-17-5035-2017

Strollo, C. M., Ziemann, P. J., 2013. Products and mechanism of secondary organic aerosol formation from the reaction of 3methylfuran with $\mathrm{OH}$ radicals in the presence of NOx. Atmos. Environ. 77, 534-543. https://doi.org/10.1016/j.atmosenv.2013.05.033

Tajuelo, M., Rodríguez, D., Baeza-Romero, M.T., Díaz-de-Mera, Y., Aranda, A., Rodríguez, A., 2019a. Secondary Organic Aerosol Formation from Styrene Photolysis and Photooxidation with $\begin{array}{lllll}\text { Hydroxyl } & \text { Radicals. } & \text { Chemosphere. } & 231, & 276\end{array}$ https://doi.org/10.1016/j.chemosphere.2019.05.136

Tajuelo, M., Rodríguez, A., Baeza-Romero, M.T., Aranda, A., Díaz-de-Mera, Y., Rodríguez, D., 2019b. Secondary organic aerosol formation from $\alpha$-methylstyrene atmospheric degradation: Role of NO level, relative humidity and inorganic seed aerosol. Atmos. Res. 230, 10463. https://doi.org/10.1016/j.atmosres.2019.104631

Thananatthanachon, T., Rauchfuss, T. B., 2010. Efficient production of the liquid fuel 2,5dimethylfuran from fructose using formic acid as a reagent. Angew Chem Int Ed Engl, 49:66166618. https://doi.org/10.1002/anie.201002267

Tong, X., Ma, Y., Li, Y., 2010. Biomass into chemicals: Conversion of sugars to furan derivatives by catalytic processes. Appl. Catal. A-Gen. 385, 1-13. https://doi.org/10.1016/j.apcata.2010.06.049 
Tsigaridis, K., Daskalakis, N., Kanakidou, M., Adams, P. J., Artaxo, P., Bahadur, R., Balkanski, Y., Bauer, S. E., Bellouin, N., Benedetti, A., Bergman, T., Berntsen, T. K., Beukes, J. P., Bian, H., Carslaw, K. S., Chin, M., Curci, G., Diehl, T., Easter, R. C., Ghan, S. J., Gong, S. L., Hodzic, A., Hoyle, C. R., Iversen, T., Jathar, S., Jimenez, J. L., Kaiser, J. W., Kirkevåg, A., Koch, D., Kokkola, H., Lee, Y. H., Lin, G., Liu, X., Luo, D. G., Ma, X., Mann, G.W., Mihalopoulos, N., Morcrette, J. J., Mülle, J.F., Myhre, G., Myriokefalitakis, S., Ng, N.L., O’Donnel, D., Penner, J. E., Pozzoli, L., Pringle, K.J., Russell, L.M., Schulz, M., Sciare, J., Seland, Ø., Shindell, D. T., Sillman, S., Skeie, R.B., Spracklen, D., Stavrakou, T., Steenrod, S. D., Takemura, T., Tiitta, P., Tilmes, S., Tost, H., van Noije, T., van Zyl, P. G., von Salzen, K., Yu, F., Wang, Z., Wang, Z., Zaveri, R.A., Zhang, H., Zhang, K., Zhang, Q., Zhang., X., 2014. The AeroCom evaluation and intercomparison of organic aerosol in global models. Atmos. Chem. Phys. 14, 10845-10895. https://doi.org/10.5194/acp-14-10845-2014

van der Werf, G. R., Randerson, J. T., Giglio, L., Collatz, G.J., Mu, M., Kasibhatla, P.S., Morton, D.C., DeFries, R.S., Jin, Y., van Leeuwen, T.T., 2010. Global fire emissions and the contribution of deforestation, savanna, forest, agricultural, and peat fires (1997-2009). Atmos. Chem. Phys. 10, 11707-11735. https://doi.org/10.5194/acp-10-11707-2010

Vasudevan, P.T., Gagnon, M.D., Briggs, M.S., 2010. Environmentally Sustainable Biofuels: The Case for Biodiesel, Biobutanol and Cellulosic Ethanol. In: Sustainable Biotechnology, Singh, O.V., Harvey, S.P. (Eds.). Elsevier, The Netherland, pp: 43-62

Wang, Y., Zhuang, G., Sun, Y., An, Z., 2006. The variation of characteristics and formation mechanisms of aerosols in dust, haze, and clear days in Beijing. Atmos. Environ. 40, 6579-6591. https://doi.org/10.1016/j.atmosenv.2006.05.066 
Wang, S.X., Xing, J., Jang, C., Zhu, Y., Fu, J.S., Hao, J., 2011. Impact assessment of ammonia emissions on inorganic aerosols in east China using response surface modeling technique. Environ. Sci. Technol. 45, 9293-9300. https://doi.org/10.1021/es2022347

Vereecken, L., Harder, H., Novelli, A., 2012. The reaction of Criegee intermediates with NO, $\mathrm{RO}_{2}$, and $\mathrm{SO}_{2}$, and their fate in the atmosphere, Phys. Chem. Chem. Phys., 14, 14682-14695. https://doi.org/10.1039/c2cp42300f

Xu, H.; Wang, C. A Comprehensive Review of 2,5-Dimethylfuran as a Biofuel Candidate. InBiofuels from LignocellulosicBiomass; WileyVCH Verlag GmbH \& Co. KGaA: 2016; pp 105-129

Ye, J., Abbatt. J. P. D., Chan. A.W.H., 2018. Novel pathway of $\mathrm{SO}_{2}$ oxidation in the atmosphere: reactions with monoterpene ozonolysis intermediates and secondary organic aerosol. Atmos. Chem. Phys. 18, 5549-5565. https://doi.org/10.5194/acp-18-5549-2018

Zhang, X., Cappa, C. D., Jathar, S. H., McVay, R. C., Ensberg, J. J., Kleeman, M. J., Seinfeld, J. H., 2014. Influence of vapor wall loss in laboratory chambers on yields of secondary organic aerosol. PNAS. 111, 5802-5807. https://doi.org/10.1073/pnas.1404727111

Zhang, P., Chen, T., Liu, J., Liu, C., Ma, J., Ma, Q., Chu, B., He. H., 2019. Impacts of $\mathrm{SO}_{2}$, Relative Humidity, and Seed Acidity on Secondary Organic Aerosol Formation in the Ozonolysis of Butyl Vinyl Ether. Environ. Sci. Technol. 53, 8845-8853. https://doi.org/10.1021/acs.est.9b02702 
Zhao, H., Holladay, J. E., Brown, H., Zhang, Z. C., 2007. Metal Chlorides in Ionic Liquid Solvents Convert Sugars to 5-Hydroxymethylfurfural. Science. 316, 1597-600. https://doi.org/10.1126/science.1141199

Zhao, D., Schmitt, S. H., Wang, M., Acir, I., Tillmann, R., Tan, Z., Novelli, A., Fuchs, H., Pullinen, I., Wegener, R., Rohrer, F., Wildt, J., Kiendler-Schar, A., Wahner, A., Mentel, T.F., 2018. Effects of $\mathrm{NOx}$ and $\mathrm{SO}_{2}$ on the secondary organic aerosol formation from photooxidation of $\alpha$-pinene and limonene. Atmos. Chem. Phys. 18, 1611-1628. https://doi.org/10.5194/acp-181611-2018.

Zhou, C. H, Xia, X., Lin, C. X., Tong D. S., Beltramini, J., 2011. Catalytic conversion of lignocellulosic biomass to fine chemicals and fuels. Chem. Soc. Rev. 40, 5588-5617. https://doi.org/10.1039/c1cs15124j 